\title{
Physical Activity in Multiple Sclerosis: A Comparative Study of Vitamin D, Brain-Derived Neurotrophic Factor and Regulatory T Cell Populations
}

\author{
A. Waschbisch $^{a} \quad$ I. Wenny ${ }^{a} \quad$ A. Tallner ${ }^{b} \quad$ S. Schwab K. Pfeifer $^{\text {b }} \quad$ M. Mäurer ${ }^{a, c}$ \\ a Department of Neurology, University Hospital Erlangen and ${ }^{b}$ Institute of Sport Science and Sport, \\ Friedrich-Alexander-University Erlangen-Nuremberg, Erlangen, and ${ }^{\complement}$ Caritas Krankenhaus Bad Mergentheim \\ $\mathrm{GmbH}$, Bad Mergentheim, Germany
}

\section{Key Words}

Multiple sclerosis $\cdot$ Exercise $\cdot$ Sport $\cdot$ Cardiorespiratory

fitness $\cdot$ HLA-G $\cdot$ Foxp3 $\cdot$ Brain-derived neurotrophic

factor $\cdot$ Vitamin $D$

\begin{abstract}
Background: Previous studies suggest beneficial effects of exercise in multiple sclerosis (MS). However, knowledge on the effects of physical activity on the immune system is limited. Objective: To assess potential relationships between cardiorespiratory fitness, cognitive function, and immune parameters in physically active and inactive MS patients. Methods: We identified 83 patients with relapsing-remitting disease, an unrestricted walking range, and stable interferon- $\beta$ treatment from our data base. Based on the subjective report of physical activity, the lower/inactive $(n=21)$ and upper/active quartiles $(n=21)$ of patients were selected. We assessed the frequency of T cells, B cells, NK cells, monocytes and regulatory $T$ cell populations by flow cytometry, measured brain-derived neurotrophic factor and vitamin D serum levels by ELISA, and conducted spiroergometry and transcranial sonography. Results: Physical activity and cardiorespiratory fitness were not associated with brain-derived neurotrophic factor, frequency of T regulatory cells or any other immune cell subpopulation. However, we found a
\end{abstract}

positive correlation of vitamin D serum levels with cardiorespiratory fitness. Conclusion: Overall, we found no negative effect of physical activity on the immune system. The association between vitamin $\mathrm{D}$ and cardiorespiratory fitness most likely reflects longer hours of sunlight exposure in active patients, suggesting a desirable 'side- effect' of physical activity.

Copyright $\odot 2012$ S. Karger AG, Basel

\section{Introduction}

Multiple sclerosis (MS) is a chronic inflammatory disease of the central nervous system that might lead to considerable physical disability due to motor weakness and spasticity. In addition, fatigue, heat sensitivity and mental depression are common problems. Although not evidence based, in the past patients were advised to avoid physical activity in order to stabilize the immune-mediated disease. Today, however, an increasing number of studies have shown beneficial effects of exercise in MS. It has been clearly shown that exercise in patients with MS provides similar physical and psychological benefits as in healthy controls. Exercise has shown promising effects on quality of life [1], depression [2] and fatigue [3], and may improve cognitive functions [4]. However, physical inac-

\section{KARGER}

Fax +4161306 1234

E-Mail karger@karger.ch

www.karger.com
(C) 2012 S. Karger AG, Basel

0014-3022/12/0682-0122\$38.00/0

Accessible online at:

www.karger.com/ene
PD Dr. M. Mäurer

Caritas Krankenhaus Bad Mergentheim GmbH

Uhlandstrasse 7

DE-97980 Bad Mergentheim (Germany)

Tel. +49793158 3401, E-Mail Mathias.Maeurer@ckbm.de 
tivity is still prevalent in MS patients $[5,6]$ and knowledge on the effects of exercise on the immune system of patients with neurological diseases is limited.

So far, no systematic analysis of the immunoregulatory effects of physical activity in MS patients has been performed. It is not clear if physical activity has such an effect at all. In addition, there is no answer to the question whether physical activity above a certain level might even be harmful due to immunological alterations. There is evidence from the literature that physical activity impacts on the human immune system and cytokine homeostasis. It has been suggested that exercise significantly induces brain-derived neurotrophic factor (BDNF) production in MS patients and controls [7]. In athletes, a profound immunosuppressive effect of exercise with decreased numbers of granulocytes, macrophage oxidative burst activity and a decrease in cytotoxic T cells was demonstrated [8].

Studies evaluating similar effects in MS patients are lacking. This is why we evaluated potential relationships between levels of physical activity and serum levels of BDNF, vitamin D and cellular immunity in relapsingremitting MS patients. Transcranial sonography and the third ventricle width as well as functional cognitive tests (MUSIC [9] and PASAT [10]) were employed to identify relationships between physical activity and cognitive function in MS patients. In order to obtain a reliable marker for physical fitness and physical activity, we assessed cardiorespiratory fitness.

Since exercise and sport are inherent parts of our modern society, we believe that the relation of physical activity and immunity is of paramount importance to the care of MS patients.

\section{Patients and Methods}

\section{Patient Selection and Clinical Samples}

The study was approved by the local ethics committee and written informed consent was obtained from all patients. Questionnaires on demographics, disease course, treatment and comorbidities were collected from 632 patients with MS as previously described [6]. Self-reported data on disease course, walking range and immunomodulatory therapy was used to identify 83 subjects with relapsing-remitting MS who had no significant comorbidities, an unrestricted walking range (EDSS $\leq 3.5$ ) and were treated with interferons at high frequency, i.e. interferon- $\beta$ la $3 \times /$ week $\left(\right.$ Rebif $^{\circledR}$ ) or interferon- $\beta$-1b (Betaferon ${ }^{\circledR}$ ).

Physical activity was evaluated using the German version [11] of the Baecke Questionnaire [12], which quantifies structured exercise (sport index), physical activity acquired in leisure time (leisure time index) and at work (occupational index). Each index adopts values from 1 to 5 , with 5 indicating the highest possible physical activity. A sport index value of 3 can be achieved by, for example, 2-3 h of moderate intensity exercise per week. The sport index was used to define quartiles of patients according to their level of physical activity. Patients that belonged to the lower $(\mathrm{n}=$ $21)$ and upper quartile $(n=21)$ were recruited for further testing. EDSS performance and relapse rates were assessed by two neurologists blinded to the sport index. Peripheral blood was obtained by venipuncture prior to spiroergometry in all patients. All samples were obtained during a period of 6 weeks between June and September 2008.

\section{Spiroergometry}

Spiroergometry was conducted on a bicycle ergometer (Kardiomed Diagnostic Cycle, Proxomed, Germany) using the Oxycon ${ }^{\circledR}$ Mobile System (Viasys Healthcare, Germany). A ramp protocol was used to assess maximum aerobic capacity $\left(\mathrm{VO}_{2 \max }\right)$ and the respiratory exchange ratio. Following a 3-min warm-up $(25 \mathrm{~W})$, the intensity was increased by $11 \mathrm{~W} / \mathrm{min}$ in female and 15 $\mathrm{W} / \mathrm{min}$ in male participants. Ergometry was conducted until subjective physical exertion and included a 3 -min cool-down period.

\section{Flow Cytometry}

Peripheral blood mononuclear cells were isolated via Ficoll density centrifugation (Lymphoprep ${ }^{\mathrm{TM}}$; Axis-Shield, Oslo, Norway). Cells were washed twice in phosphate-buffered saline containing $0.1 \%$ sodium azide and $1 \%$ bovine serum albumin, followed by Fc receptor blocking with human IgG (Sigma-Aldrich, Munich, Germany). Afterwards, cells were incubated for $30 \mathrm{~min}$ with specific, fluorescence-conjugated monoclonal antibodies. The following anti-human monoclonal antibodies were used: anti-CD3 (HIT3a), anti-CD4 (SK3), anti-CD8 (SK1), anti-CD14 (MOP9), anti-CD19 (HIB19), anti-CD16 (3G8), anti-CD25 (MA251) (all from BD Biosciences, Heidelberg, Germany) and antiHLA-G (MEM-G/9) (Exbio, Prague, Czech Republic). Intracellular stainings using anti-Foxp3 (PCH101) antibody were performed using the Foxp3 staining kit (eBioscience, San Diego, Calif., USA) according to the manufacturer's protocol. The respective isotype controls were purchased from BD Biosciences or eBioscience. All antibodies were titrated for optimal concentrations. Samples were measured on a FACSCalibur (surface stainings) or FACSCanto II (intracellular staining) flow cytometer (BD Biosciences). Data was analyzed using FlowJo Software, Version 8.8.6 (Tree Star, Ashland, Oreg., USA).

\section{ELISA}

Vitamin D serum levels were analyzed using a 25-OH-vitamin D enzyme immunoassay (Immunodiagnostic Systems, Frankfurt, Germany) according to the manufacturer's instructions. For the analysis of BDNF concentrations in serum samples the Quantikine ${ }^{\circledR}$ Human BDNF Immunoassay (R\&D Systems, Wiesbaden, Germany) was used.

\section{Transcranial Sonography}

The diameter of the third ventricle was assessed using a standardized transcranial sonography protocol as previously described [13]. All patients were assessed by one independent, experienced examiner who was unaware of the degree of physical activity or clinical details of the patient. Transcranial sonography of the third ventricle was supervised by M.M. 
Table 1. Basic demographic and clinical characteristics of inactive and active relapsing-remitting MS patients

\begin{tabular}{|c|c|c|c|c|c|c|c|c|}
\hline & $\begin{array}{l}\text { Sport } \\
\text { index }\end{array}$ & Age, years & $\begin{array}{l}\text { Sex ratio } \\
\mathrm{m}: \mathrm{f}\end{array}$ & BMI & EDSS & $\begin{array}{l}\text { Disease } \\
\text { duration } \\
\text { years }\end{array}$ & $\begin{array}{l}\text { Relapses } \\
\text { in the last } \\
2 \text { years }\end{array}$ & $\begin{array}{l}\text { Relative } \\
\mathrm{VO}_{2 \text { peak }} \\
\% \text { of normal }\end{array}$ \\
\hline Active patients & $3.6 \pm 0.6$ & $39 \pm 8.3$ & $1: 3$ & $23.3 \pm 2.9$ & $1.44 \pm 1.0$ & $7.8 \pm 6.5$ & $0.95 \pm 0.97$ & $117.3 \pm 15.6$ \\
\hline Inactive patients & $2.33 \pm 0.5$ & $36 \pm 8.3$ & $1: 5$ & $23.5 \pm 3.7$ & $1.21 \pm 0.9$ & $6.3 \pm 4.7$ & $1.60 \pm 1.64$ & $94.9 \pm 20.1$ \\
\hline Group difference & $\mathrm{p}<0.0001$ & n.s. & n.s. & n.s. & n.s. & n.s. & n.s. & $\mathrm{p}=0.0003$ \\
\hline
\end{tabular}

Cognitive Function Tests

The MUSIC (Multiple Sclerosis Inventarium Cognition [9]) and PASAT (Paced Auditory Serial Addition Test [10]) were performed according to the protocol.

\section{Statistical Analysis}

All data was analyzed using GraphPad Prism ${ }^{\circledR}$ Software. A Shapiro-Wilk normality test was employed and group differences were assessed by a two-tailed Student's t or a Mann-Whitney U test. Where applicable, Spearman or Pearson coefficients were calculated to assess bivariate correlations.

\section{Results}

\section{Clinical Details and Physical Performance of the} Study Population

There were no significant differences concerning basic demographic and disease-specific parameters between physically active and inactive patients (table 1). Self-reported physical activity as assessed by the Baecke Questionnaire correlated well with physical performance parameters (relative $\mathrm{VO}_{2 \text { peak }}$ (percentage of age and genderspecific normative values of healthy subjects), $r=0.61$, $\mathrm{p}<0.0001$; relative maximum Watt (percentage of normative values), $r=0.60, \mathrm{p}<0.0001$ ). The absolute VO2 peak values were within the range of normative values for healthy adults [14] but differed significantly between the group of active (34.69 \pm 8.36$)$ and inactive patients (27.31 $\pm 6.09)$. The duration of the test was higher for the active group (14:25 \pm 3:09 $\mathrm{min})$ compared to the inactive group (11:07 \pm 03:20 $\mathrm{min})$. Of note, the peak respiratory exchange rate did not differ between the two groups (active: $1.16 \pm 0.06$; inactive: $1.17 \pm 0.07$ ), indicating adequate and comparable physical exertion in both groups.

\section{Cognitive Function, Third Ventricle Diameter and}

$B D N F$ in Active and Inactive MS Patients

Sedentary and active MS patients performed comparably in cognitive function tests (PASAT inactive: $0.08 \pm$
1.67, active: $-0.51 \pm 1.57, \mathrm{p}=0.11$ ); MUSIC inactive: 26.4 \pm 4.6 , active: $23.7 \pm 4.7, \mathrm{p}=0.074$ ). There were no significant differences concerning the diameter of the 3rd ventricle between the group of inactive and active MS patients (fig. 1a). Basal BDNF serum levels were within the range of previously published data on healthy controls [15] and did not differ between active and sedentary MS patients (fig. 1b). In line with that, there were no correlations of cognitive tests, ventricle diameter or BDNF levels with any of the physical performance parameters.

\section{Immune Cell Subpopulations in Physically Active and} Inactive Patients

Basic parameters of cellular immunity were assessed by flow cytometry. The percentages of circulating monocytes, CD4+ T cells, CD8+ T cells, B cells and NK cells were within the normal range in both groups (as exemplarily depicted for T and B lymphocytes, fig. 2). No differences were observed between inactive and active MS patients. The frequency of Foxp $3+\mathrm{T}$ regulatory cells within the peripheral blood did not differ between active $(5.3 \pm 1.99 \%$ of CD $4+\mathrm{T}$ cells) and inactive $(6.1 \pm 2.01 \%$ of CD4+ T cells) MS patients and did not correlate with physical performance parameters (fig. 2). In line with that we found no differences concerning the percentages of CD4+HLA-G+ T regulatory cells or CD8+ T cells and monocytes that stained positive for the immune-tolerogenic molecule HLA-G (data not shown).

\section{Vitamin D Serum Levels in Physically Active and Inactive MS Patients}

The 25-OH-vitamin D serum levels of MS patients were within the normal range (mean $91.02 \pm 34.61$ $\mathrm{nmol} / \mathrm{l})$. However, there was a trend towards higher $25-\mathrm{OH}$-vitamin $\mathrm{D}$ serum levels in active versus inactive MS patients, and 25-OH-vitamin D serum levels were positively correlated with $\mathrm{VO}_{2 \text { peak }}$ as an objective parameter of physical performance ( $\mathrm{r}=0.4$, $\mathrm{p}<0.01$; fig. 3$) .81 \%$ of active MS patients reported outdoor activities that may 


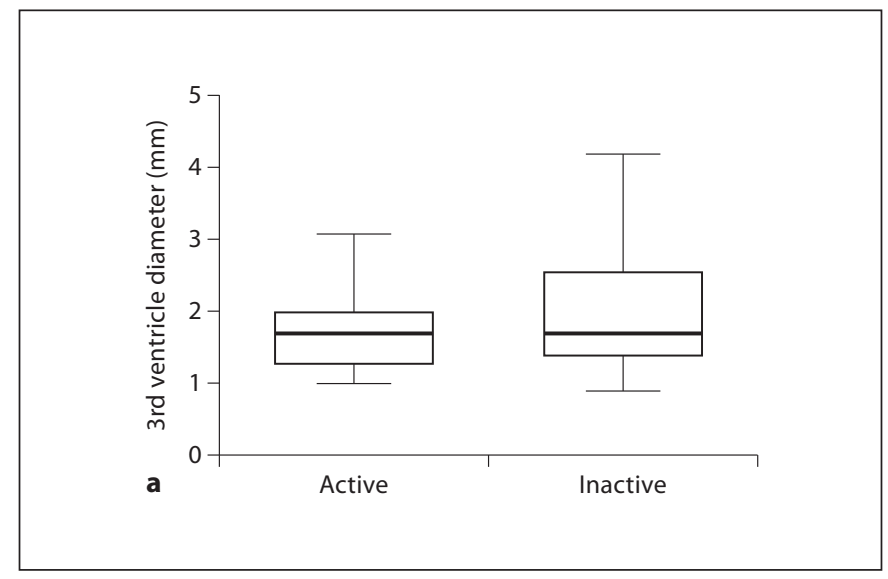

Fig. 1. Ventricular width and BDNF serum levels do not correlate with physical activity in relapsing-remitting MS patients. Transcranial sonography demonstrated no differences in the 3rd ventricle diameter between active $(n=21)$ and inactive $(n=21)$ pa-

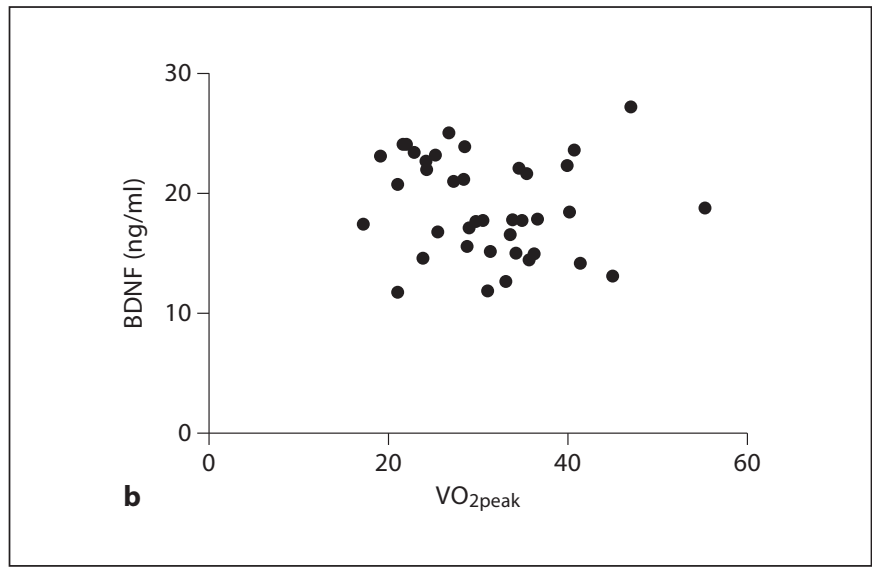

tients with relapsing-remitting MS (a). BDNF serum levels as assessed by ELISA showed no association with physical activity or parameters of cardiorespiratory fitness as exemplarily depicted for $\mathrm{VO}_{2 \text { peak }}(\mathbf{b})$.
Fig. 2. Immune cell subpopulations in physically active and inactive relapsing-remitting patients. Percentages of circulating CD4+ and CD8+ T cells, CD19+ B cells and Foxp3+ T regulatory cells (Tregs) do not differ between physically active and inactive MS patients as assessed by flow cytometry.

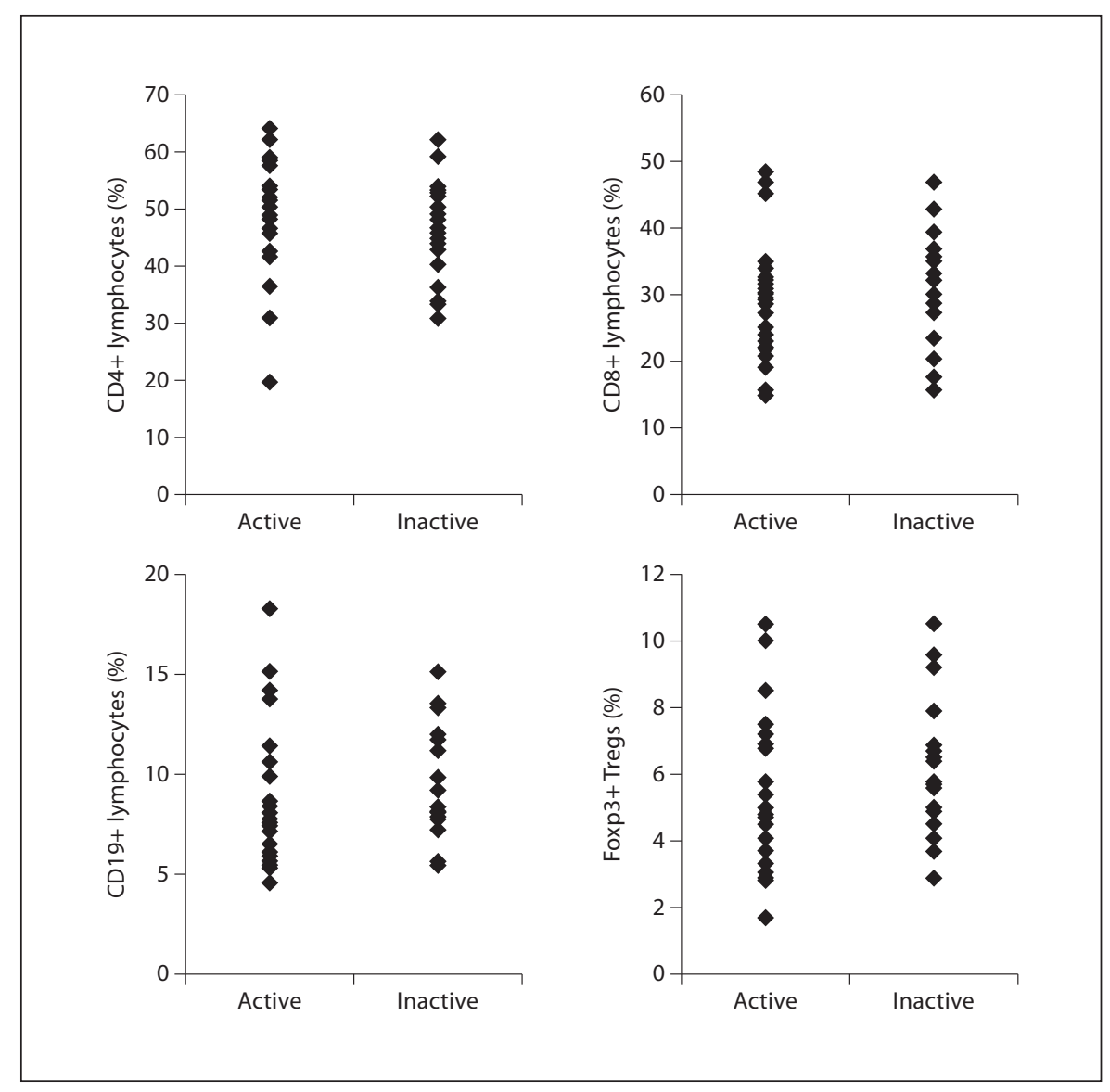






Fig. 3. Vitamin D serum levels and cardiorespiratory fitness in relapsing-remitting $\mathrm{MS}$ patients. 25-OH-vitamin $\mathrm{D}$ serum levels as assessed by ELISA are positively correlated with $\mathrm{VO}_{2 \text { peak }}$ as a parameter of cardiorespiratory fitness $(n=42)$.

account for longer hours of sunlight exposure such as Nordic Walking, jogging, cycling or horse riding as their primary and/or secondary leisure activity. There was no statistically significant association of vitamin D serum levels and circulating Foxp3 $+\mathrm{T}$ regulatory cells in our study population.

\section{Discussion}

The assessment of physical activity via questionnaire is not without pitfalls but considered appropriate in MS patients $[6,16]$. The psychometric properties of the Baecke Questionnaire have been confirmed for non-diseased populations [17]. There are no validation studies with MS patients, which might be a drawback. However, the Baecke Questionnaire has shown sensitivity to change in exercise interventions with MS patients [18].

In line with previous reports we found significant correlations between self-reported physical activity and $\mathrm{VO}_{2 \text { peak }}$ as an objective measurement of cardiorespiratory fitness [19] in MS patients, which legitimated our recruitment strategy. Interestingly, compared to our study, others have reported considerably lower absolute $\mathrm{VO}_{2 \text { peak }}$ values in MS patients $[19,20]$. Since neurological disability was reported as an independent risk factor for low cardiorespiratory fitness [19], the high $\mathrm{VO}_{2 \text { peak }}$ values in our study might be explained by the exclusion of patients with a restricted walking range, resulting in a very low mean EDSS of 1.35 in our study population. The reason for ex- cluding these patients was the conduction of a performance test (spiroergometry), which could possibly not have been interpreted properly in patients with early fatigability of the lower extremities, and the overall intention to study the effects of physical activity on the immune system during the early, inflammatory phase of the disease.

Cognitive dysfunction is prevalent in individuals with MS and treatment options are very limited. Exercise has consistently been reported to improve cognitive function in the elderly with beneficial effects on information processing speed, learning, memory and executive function $[21,22]$. In contrast, little is known on the effects of exercise or physical fitness on cognitive function in MS patients. In a limited number of patients, significant correlations were reported between $\mathrm{VO}_{2 \text { peak }}$, performance in the Paced Auditory Serial Addition Test and functional MRI parameters [23]. In addition $\mathrm{VO}_{2 \text { peak }}$ and PASAT results were found to be positively correlated with MRI surrogate markers of disease such as grey matter volume and white matter integrity [24]. Instead of performing MRI we measured the width of the 3rd ventricle by transcranial sonography, which had previously been described as a good correlate of neurocognitive function in MS patients $[13,25]$. We failed to detect an association of cardiorespiratory fitness or self-reported physical activity with performance in cognitive function tests (PASAT, MUSIC) or transcranial sonography in our small sample size, which is most likely due to differences in patient selection (e.g. exclusion of patients with secondary progressive disease). BDNF has been reported to play an important role in neural repair and plasticity. Physical activity may modulate BDNF serum levels and thereby contribute to the beneficial effects of exercise on cognitive functions [15]. Whether basal BDNF serum levels of MS patients are higher [26], lower [27,28] or equal [7] to controls is a subject of ongoing debate. Nevertheless, it has been suggested that acute exercise induces circulating BDNF in individuals with MS [7]. The fact that circulating BDNF did not differ between physically active and inactive patients with MS nor correlate with cardiorespiratory fitness in our study argues against a long-term induction of BDNF in response to exercise in MS and is in line with a previous report [28]. However, based on our ex vivo analysis, we cannot preclude that physical activity modulates BDNF secretion by immune cells at the site of inflammation.

T regulatory cells play a key role in the maintenance of peripheral immune tolerance and are protective in autoimmune diseases. Tai Chi Chuan, a traditional Chinese 
martial art, that is considered as moderate exercise has been reported to increase the numbers of circulating $T$ regulatory cells in healthy adults [29] and patients with type 2 diabetes [30]. Likewise, repeated bouts of exercise were found to increase the number and function of T regulatory cells in a murine ovalbumin-driven asthma model [31]. In our study the frequency of T regulatory cells did not correlate with physical performance parameters. Therefore, it seems unlikely that expansion of either Foxp3+ T regulatory cells or CD4+HLA-G+, a novel potent regulatory T cell subset [32], contributes to the beneficial effects of regular exercise in MS.

In this study, we only included patients on a stable high-dose high-frequency interferon therapy in order to evaluate a homogenous population of MS patients with stable disease. However, interferon- $\beta$ has previously been demonstrated to affect the $\mathrm{T}$ regulatory cell compartment [33] and was reported to induce BDNF secretion in immune cells $[34,35]$. Therefore, we cannot exclude that pleiotropic 'beneficial' interferon effects overlay the potential immunological effects of physical activity.

Nevertheless, the most important finding of our study is that, in terms of immunology, physical activity has no effects on proinflammatory components of the immune systems and therefore no potential negative effects for MS patients who are physically active.
Vitamin D has recently emerged as a protective factor against the development of MS and its therapeutic value is currently evaluated in randomized controlled trials [36]. In line with previously published findings in healthy individuals [37, 38], we found an association between physical activity and vitamin D levels which may be considered to be secondary to outdoor exercise and sunlight exposure. The finding that vitamin $\mathrm{D}$ serum levels correlate with $\mathrm{VO}_{2 \text { peak }}$ most likely reflects the longer hours of sunlight exposure in patients performing outdoor activities and should therefore be considered as a desirable effect of a well-tolerated, supportive treatment in MS. We hope to encourage further studies evaluating the therapeutic effect of physical activity on MS that will eventually lead to the introduction of physical exercise as another mainstay of MS therapy.

\section{Acknowledgement}

This study has been financially supported by Bayer Vital $\mathrm{GmbH}$.

\section{Disclosure Statement}

The authors declare that they have no conflicts of interest.

\section{References}

1 Motl RW, Gosney JL: Effect of exercise training on quality of life in multiple sclerosis: a meta-analysis. Mult Scler 2008;14:129-135.

2 Rasova K, Havrdova E, Brandejsky P, Zalisova M, Foubikova B, Martinkova P: Comparison of the influence of different rehabilitation programmes on clinical, spirometric and spiroergometric parameters in patients with multiple sclerosis. Mult Scler 2006;12: 227-234.

3 Andreasen AK, Stenager E, Dalgas U: The effect of exercise therapy on fatigue in multiple sclerosis. Mult Scler 2011;17:1041-1054.

4 Motl RW, Sandroff BM, Benedict RH: Cognitive dysfunction and multiple sclerosis: developing a rationale for considering the efficacy of exercise training. Mult Scler 2011;17: 1034-1040.

5 Motl RW, McAuley E, Snook EM: Physical activity and multiple sclerosis: a meta-analysis. Mult Scler 2005;11:459-463.

6 Tallner A, Waschbisch A, Wenny I, Schwab S, Hentschke C, Pfeifer K, Maurer M: Multiple sclerosis relapses are not associated with exercise. Mult Scler 2012;18:232-235.
7 Gold SM, Schulz KH, Hartmann S, Mladek M, Lang UE, Hellweg R, Reer R, Braumann $\mathrm{KM}$, Heesen C: Basal serum levels and reactivity of nerve growth factor and brain-derived neurotrophic factor to standardized acute exercise in multiple sclerosis and controls. J Neuroimmunol 2003;138:99-105.

8 Nieman DC: Special feature for the Olympics: effects of exercise on the immune system: exercise effects on systemic immunity. Immunol Cell Biol 2000;78:496-501.

9 Calabrese P, Kalbe E, Kessler J: Das Multiple Sklerose Inventarium Cognition (MUSIC). NeuroPsycho 2004;30:384-388.

10 National Multiple Sclerosis Society: http:// www.nationalmssociety.org/forprofessionals/researchers/clinical-study-measures/pasat/download.Aspx?Id=259.

11 Wagner P, Singer R: Ein Fragebogen zur Erfassung der habituellen körperlichen Aktivität verschiedener Bevölkerungsgruppen. Sportwissenschaft 2003;33:383-397.

12 Baecke JA, Burema J, Frijters JE: A short questionnaire for the measurement of habitual physical activity in epidemiological studies. Am J Clin Nutr 1982;36:936-942.
13 Berg D, Maurer M, Warmuth-Metz M, Rieckmann P, Becker G: The correlation between ventricular diameter measured by transcranial sonography and clinical disability and cognitive dysfunction in patients with multiple sclerosis. Arch Neurol 2000; 57:1289-1292.

14 American College of Sports Medicine: ACSM's Guidelines for Exercise Testing and Prescription. Baltimore, Md., Lippincott, Williams and Wilkins, 2006.

15 Knaepen K, Goekint M, Heyman EM, Meeusen R: Neuroplasticity - exercise-induced response of peripheral brain-derived neurotrophic factor: a systematic review of experimental studies in human subjects. Sports Med 2010;40:765-801.

16 Snook EM, Motl RW, Gliottoni RC: The effect of walking mobility on the measurement of physical activity using accelerometry in multiple sclerosis. Clin Rehabil 2009;23: 248-258. 
17 van Poppel MN, Chinapaw MJ, Mokkink LB, van Mechelen W, Terwee CB: Physical activity questionnaires for adults: a systematic review of measurement properties. Sports Med 2010;40:565-600.

18 Mostert S, Kesselring J: Effects of a shortterm exercise training program on aerobic fitness, fatigue, health perception and activity level of subjects with multiple sclerosis. Mult Scler 2002;8:161-168.

19 Motl RW, Goldman M: Physical inactivity, neurological disability, and cardiorespiratory fitness in multiple sclerosis. Acta Neurol Scand 2011;123:98-104.

20 Romberg A, Virtanen A, Aunola S, Karppi SL, Karanko H, Ruutiainen J: Exercise capacity, disability and leisure physical activity of subjects with multiple sclerosis. Mult Scler 2004;10:212-218.

21 Heyn P, Abreu BC, Ottenbacher KJ: The effects of exercise training on elderly persons with cognitive impairment and dementia: a meta-analysis. Arch Phys Med Rehabil 2004; 85:1694-1704.

22 Smith PJ, Blumenthal JA, Hoffman BM, Cooper H, Strauman TA, Welsh-Bohmer K, Browndyke JN, Sherwood A: Aerobic exercise and neurocognitive performance: a meta-analytic review of randomized controlled trials. Psychosom Med 2010;72:239-252.

23 Prakash RS, Snook EM, Erickson KI, Colcombe SJ, Voss MW, Motl RW, Kramer AF: Cardiorespiratory fitness: a predictor of cortical plasticity in multiple sclerosis. Neuroimage 2007;34:1238-1244.

24 Prakash RS, Snook EM, Motl RW, Kramer AF: Aerobic fitness is associated with gray matter volume and white matter integrity in multiple sclerosis. Brain Res 2010;1341:4151.
25 Walter U, Horowski S, Benecke R, Zettl UK: Transcranial brain sonography findings related to neuropsychological impairment in multiple sclerosis. J Neurol 2007;254 (suppl 2):II49-II52.

26 Yoshimura S, Ochi H, Isobe N, Matsushita T, Motomura K, Matsuoka T, Minohara M, Kira J: Altered production of brain-derived neurotrophic factor by peripheral blood immune cells in multiple sclerosis. Mult Scler 2010;16:1178-1188.

27 Azoulay D, Vachapova V, Shihman B, Miler A, Karni A: Lower brain-derived neurotrophic factor in serum of relapsing remitting MS: reversal by glatiramer acetate. J Neuroimmunol 2005;167:215-218.

28 Castellano V, White LJ: Serum brain-derived neurotrophic factor response to aerobic exercise in multiple sclerosis. J Neurol Sci 2008; 269:85-91.

29 Yeh SH, Chuang H, Lin LW, Hsiao CY, Eng HL: Regular Tai Chi Chuan exercise enhances functional mobility and CD4CD25 regulatory T cells. Br J Sports Med 2006;40:239243.

30 Yeh SH, Chuang H, Lin LW, Hsiao CY, Wang PW, Yang KD: Tai Chi Chuan exercise decreases A1C levels along with increase of regulatory T-cells and decrease of cytotoxic Tcell population in type 2 diabetic patients. Diabetes Care 2007;30:716-718.

31 Lowder T, Dugger K, Deshane J, Estell K, Schwiebert LM: Repeated bouts of aerobic exercise enhance regulatory $\mathrm{T}$ cell responses in a murine asthma model. Brain Behav Immun 2010;24:153-159.
32 Feger U, Tolosa E, Huang YH, Waschbisch A, Biedermann T, Melms A, Wiendl H: HLA-G expression defines a novel regulatory T-cell subset present in human peripheral blood and sites of inflammation. Blood 2007;110: 568-577.

33 Korporal M, Haas J, Balint B, Fritzsching B, Schwarz A, Moeller S, Fritz B, Suri-Payer E, Wildemann B: Interferon beta-induced restoration of regulatory $\mathrm{T}$-cell function in multiple sclerosis is prompted by an increase in newly generated naive regulatory $\mathrm{T}$ cells. Arch Neurol 2008;65:1434-1439.

34 Azoulay D, Mausner-Fainberg K, Urshansky N, Fahoum F, Karni A: Interferon-beta therapy up-regulates BDNF secretion from PBMCs of MS patients through a CD40-dependent mechanism. J Neuroimmunol 2009; 211:114-119.

35 Lalive PH, Kantengwa S, Benkhoucha M, Juillard C, Chofflon M: Interferon-beta induces brain-derived neurotrophic factor in peripheral blood mononuclear cells of multiple sclerosis patients. J Neuroimmunol 2008;197:147-151.

36 Ascherio A, Munger KL, Simon KC: Vitamin $\mathrm{D}$ and multiple sclerosis. Lancet Neurol 2010;9:599-612.

37 Absoud M, Cummins C, Lim MJ, Wassmer E, Shaw N: Prevalence and predictors of vitamin D insufficiency in children: A Great Britain population based study. PLoS One 2011;6:e22179.

38 Farrell SW, Willis BL: Cardiorespiratory fitness, adiposity, and serum 25-dihydroxyvitamin D levels in women: the Cooper Center Longitudinal Study. J Womens Health 2012;21:80-86 